\title{
Metastasis of Hepatocellular Carcinoma to the Ovary: A Case Report and Review of the Literature
}

\author{
Jae-Myeong Lee*, Kwang-Min Park ${ }^{\dagger}$, So-Young Lee ${ }^{\ddagger}$, Julian Choi ${ }^{\dagger}$, Dae Wook Hwang ${ }^{\dagger}$, and Young-Joo Lee ${ }^{\dagger}$ \\ *Department of Surgery, Ajou University School of Medicine, Suwon, ${ }^{\dagger}$ Division of Hepato-Biliary \& Pancreas Surgery, Department of Surgery, \\ and ${ }^{\ddagger}$ Department of Pathology, Asan Medical Center, University of Ulsan College of Medicine, Seoul, Korea
}

Metastasis of hepatocellular carcinoma (HCC) to the ovary is notably rare. We present a case of HCC metastasis to the ovary with a review of the literature, which includes only 7 reported cases. A 43-year-old hepatitis B virus carrier was admitted with a right ovarian cystic mass. She had been diagnosed with HCC 2 years prior, for which she underwent transarterial chemoembolization followed by right posterior sectionectomy. Eight months after the hepatectomy, the first intrahepatic recurrence was detected and treated with transarterial chemoembolization. An additional intrahepatic recurrence occurred 12 months after transarterial chemoembolization and was managed with left medial sectionectomy and intra-operative radiofrequency ablation. Over the following 3 months, the patient developed elevated alpha-fetoprotein, and positron emission tomography showed a cystic mass in the right side of the pelvic cavity with focal hypermetabolic activity, which suggested a site of recurrent HCC. An exploratory laparotomy was performed, and a soft, ovoid cystic mass was identified in the right ovary. There was no evidence of metastases in the liver, left ovary, or peritoneum. Because of the absence of tumor on the surface of the ovary and the lack of peritoneal seeding, the mode of metastasis was thought to be hematogenous. Therefore, a right salphingooophorectomy was performed. The pathological features showed metastatic HCC with clear resection margins. Although metastasis of $\mathrm{HCC}$ to the ovary is very rare, it should be suspected in a female patient with a lower abdominal mass and an elevated serum AFP level in the absence of other demonstrable metastases. (Gut Liver 2011;5:543-547)

Key Words: Hepatocellular carcinoma; Metastasis; Ovary

\section{INTRODUCTION}

Hepatocellular carcinoma (HCC) spreads via the hematogenous route, the lymphatic route, or by direct invasion into adjacent organs. ${ }^{1}$ The common extrahepatic metastatic sites of HCC are the lungs, peritoneum, adrenal glands, and bone, ${ }^{2}$ although there are rare reports of metastases to the heart, ${ }^{3}$ nasal cavity, ${ }^{4}$ orbital cavity, ${ }^{5}$ skin, ${ }^{6}$ external auditory canals, ${ }^{7}$ and pharynx. ${ }^{8}$ The ovary is a rare site of metastasis for HCC, which was first reported in $1983 .^{9}$ In the English literature, there have been 6 reported cases of metastatic HCC to the ovary and 4 cases reported in the Korean literature. We present a case of metastatic HCC to the ovary with a review of the literature.

\section{CASE REPORT}

A 43-year-old woman with a history of HCC secondary to chronic infection with hepatitis B virus (HBV) was admitted to the hospital for evaluation of a right ovarian cystic mass. She also had a family history of HBV in two of her siblings. She was diagnosed with HCC 2 years ago and underwent transarterial chemoembolization (TACE), followed by right posterior sectionectomy. Eight months after the hepatectomy, the first intrahepatic recurrence was detected, which was treated with TACE. An additional intrahepatic recurrence occurred 12 months after TACE, which was managed with left medial sectionectomy and intra-operative radiofrequency ablation.

During the 3-month follow-up period after the second hepatectomy, the patient developed an elevated alpha-fetoprotein (AFP; 336,520 ng/ $\mu \mathrm{L}$ [normal range, 0 to $7 \mathrm{ng} / \mu \mathrm{L}]$ ). However, a liver dynamic computed tomography (CT) and chest CT showed no evidence of recurrent HCC. A positron emission tomography (PET) showed a hypermetabolic lesion $(\max \mathrm{SUV}=4.5$ in the

\footnotetext{
Correspondence to: Kwang-Min Park

Division of Hepato-Biliary \& Pancreas Surgery, Department of Surgery, Asan Medical Center, University of Ulsan College of Medicine, 86 Asanbyeongwon-gil, Songpa-gu, Seoul 138-736, Korea

Tel: +82-2-3010-3493, Fax: +82-2-3010-6701, E-mail: kmpark@amc.seoul.kr Received on July 6, 2010. Accepted on August 25, 2010. pISSN 1976-2283 eISSN 2005-1212 http://dx.doi.org/10.5009/gnl.2011.5.4.543

() This is an Open Access article distributed under the terms of the Creative Commons Attribution Non-Commercial License (http://creativecommons.org/licenses/by-nc/3.0) which permits unrestricted non-commercial use, distribution, and reproduction in any medium, provided the original work is properly cited.
} 

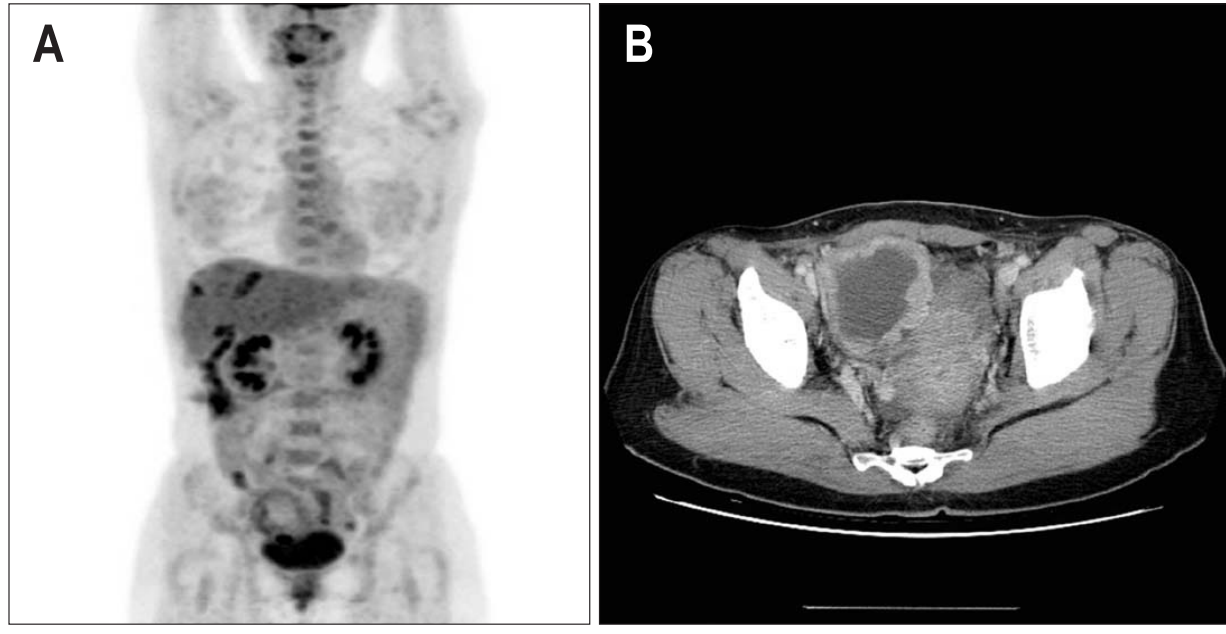

Fig. 1. (A) Fusion whole-body positron emission tomography scan shows a 6-cm cystic lesion in the right pelvic cavity and a more focal hypermetabolic lesion in the inferior portion. (B) Abdominopelvic computed tomography reveals a $7-\mathrm{cm}$ heterogeneous mass in the right ovary, which suggested that metastatic hepatocellular carcinoma was more likely than primary ovarian cancer.

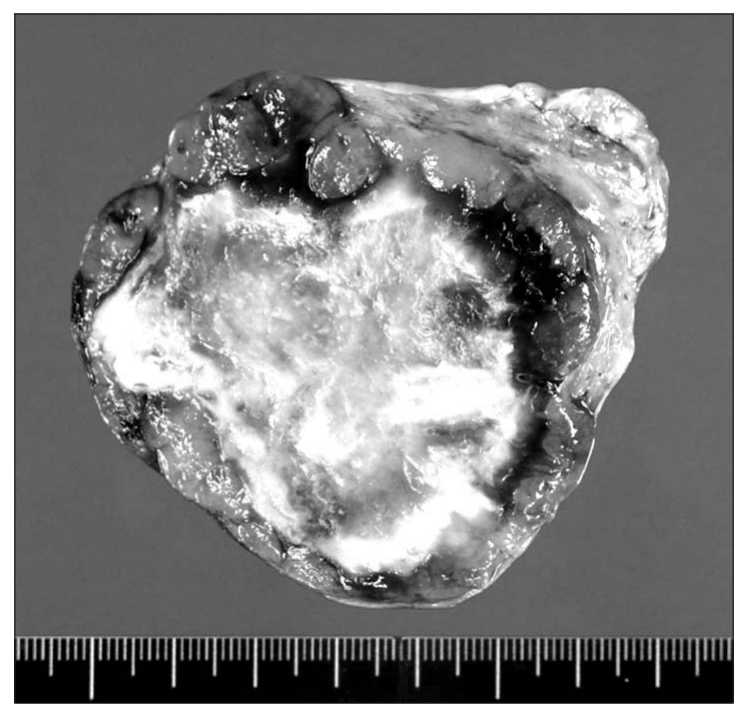

Fig. 2. The gross features of the right ovarian mass. It is a $7 \times 6 \times 5 \mathrm{~cm}$ tumor with a pink-yellow, soft, granular cut surface.

right side of pelvic cavity), suggesting the site of recurrent HCC. Further examination of the abdominopelvic CT revealed a right ovarian cystic mass (Fig. 1).

Since the metastasis was limited to the right ovary without evidence of widespread recurrence, she was recommended to undergo an exploratory laparotomy with removal of the right ovarian mass. At laparotomy, there was no evidence of metastases in the liver, left ovary, or peritoneum. A soft, ovoid, cystic mass was identified in the right ovary and the frozen section confirmed metastatic HCC. Because of the absence of tumor on the surface of the ovary and the lack of peritoneal seeding, the mode of metastasis was thought to be hematogenous. Therefore, a right salphingo-oophorectomy (SO) was performed.

On the final pathologic examination, the right ovary showed a $7 \times 6 \times 5 \mathrm{~cm}$ sized tumor with a pink-yellow, soft, granular cut surface (Fig. 2). The tumor cells showed the typical trabecular pattern of HCC and had very similar features to the previously resected HCC mass. The tumor was compatible with metastatic
HCC and there was no evidence of lymphovascular or perineural invasion. The ovarian capsule was intact and the fallopian tube had no tumor (Fig. 3).

\section{DISCUSSION}

HCC rarely metastasizes to the ovary. Moreover, metastatic HCC should be distinguished from a hepatoid yolk sac tumor and a primary hepatoid carcinoma of the ovary. ${ }^{10}$ Hepatoid carcinomas of the ovary and hepatoid yolk sac tumors are suspected when there is no clinical or operative evidence of HCC.

Hepatoid yolk sac tumors usually occur in females of reproductive age with germ cell neoplastic components or gonadal dysgenesis. ${ }^{10}$ Young et al. ${ }^{11}$ suggested that canaliculi are strongly suggestive of metastatic HCC rather than hepatoid yolk sac tumors.

Hepatoid carcinomas of the ovary have recently been described as a distinctive type of carcinoma that arises outside the liver, but to a considerable extent resembles HCC both histologically and immunohistochemically due to its staining for AFP. ${ }^{11}$ Hepatoid carcinomas of the ovary generally occur in older patients and the presence of focal staining for AFP is essential for a certain diagnosis of in a site as unusual as the ovary. ${ }^{10}$ Hepatoid carcinomas of the ovary can also present in the stomach, pancreas, lungs, kidneys, and urinary bladder. ${ }^{12}$ Because hepatoid carcinomas of the ovary are usually metastatic from the stomach and leave a lesion on the surface of the ovary, the existence of a hepatoid carcinoma outside the ovary and tumor growth on the surface of the ovary can elevate the possibility of a hepatoid carcinoma of the ovary.

In the case presented herein, the patient had a history of HCC and there was no evidence of hepatoid carcinomas in other abdominal organs. Furthermore, the pathologic features suggested HCC without any features of haptoid yolk sac tumors, such as germ cells or gonadal dysgenesis. There was also no tumor on the ovarian capsule or peritoneal cavity, thus the tumor was likely to have metastasized from the primary HCC by hematog- 

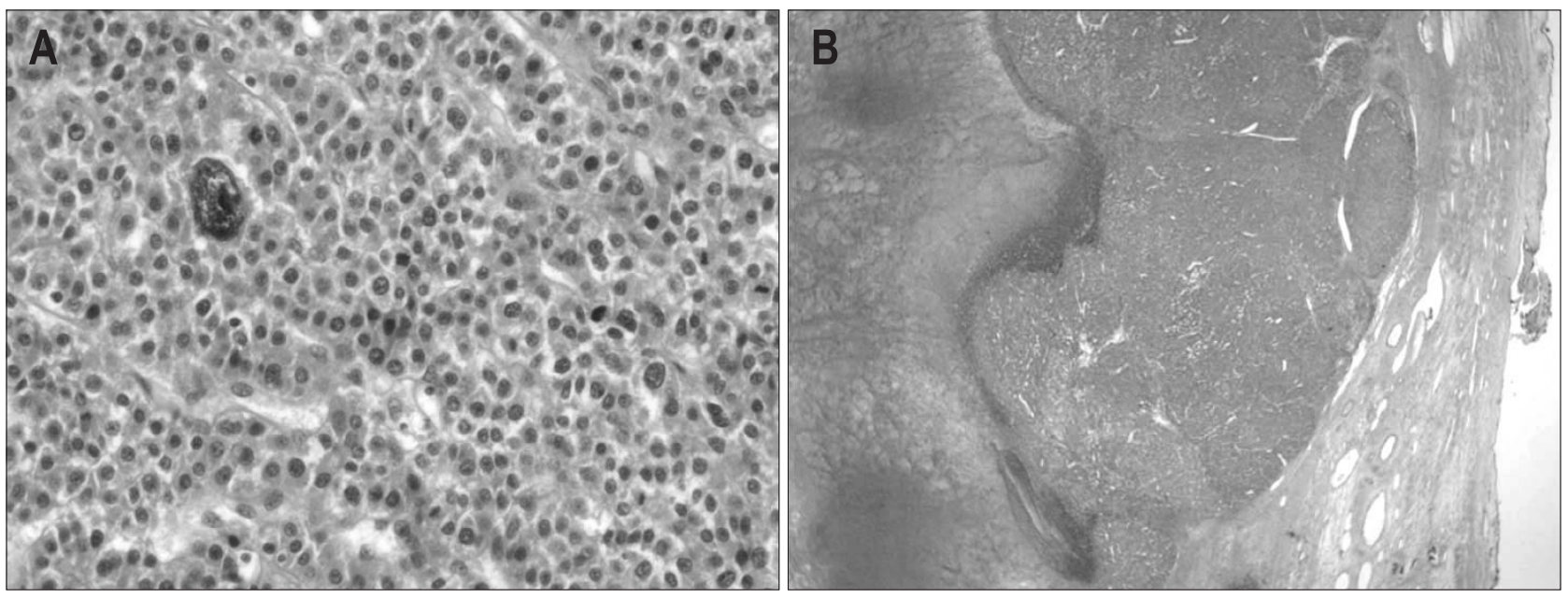

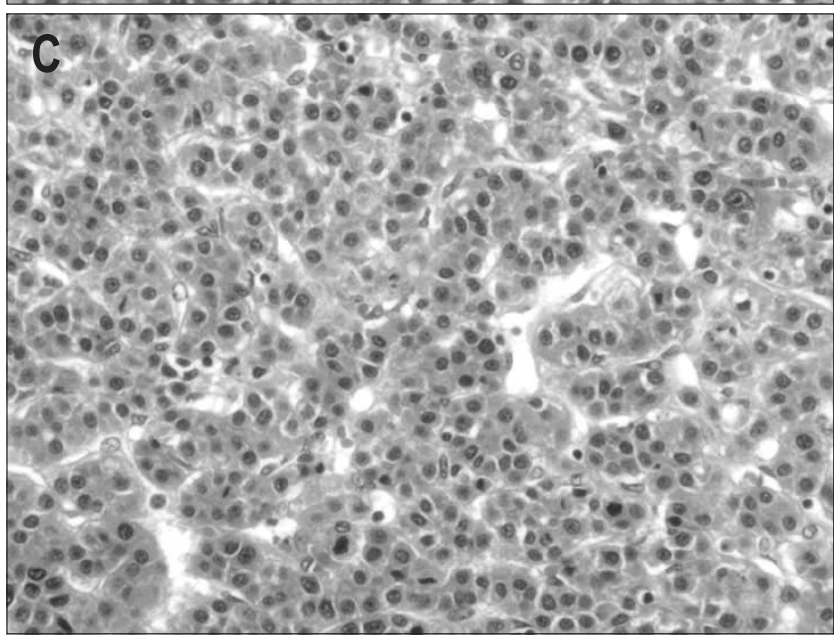

enous spread.

Ten cases of previously reported metastatic HCCs to the ovary are summarized and presented in Table 1 . The mean age of the 10 cases and the current case was 45.6 years (range, 31 to 68 years). The number of right, left, and bilateral HCC ovarian metastases were 4, 4, and 3, respectively. In 7 patients, the ovarian metastases were noted during follow-up, of which 3 patients showed no clinical symptoms or signs (case no. 1, 2, and 8). The other 4 patients were diagnosed as synchronous ovarian metastases (case no. 3, 4, 5, and 10).

All cases were treated surgically, except 3 cases (case no. 7, 8 , and 10), which showed multiple lung, spleen, and para-aortic lymph node metastases (case no. 7) or peritoneal carcinomatosis (case no. 8 and 10). The surgical procedures performed included bilateral SO with or without transabdominal hysterectomy. In our case, we made the decision to perform a unilateral SO; the decision was based on the fact that there was no evidence of peritoneal spread or ovarian capsular involvement. In view of the likely hematogenous spread, a limited resection was performed. There was no clear oncologic evidence to support performing an extensive bilateral SO and hysterectomy with the increased risk of operative morbidity and hormonal consequences.
Fig. 3. Microscopic features of primary hepatocellular carcinoma (HCC) (A) and HCC metastasis to the ovary (B, C). (A) Previously resected primary HCC. The typical trabecular pattern of HCC is shown (x400). (B) A hypercellular nodular mass on the ovary with focal hemorrhage and necrosis. The ovarian cortex is intact, and no normal ovarian cortex is identified (x10). (C) Polygonal tumor cells with vesicular nuclei and prominent nucleoli are separated by sinusoids. The HCC metastasized to the ovary is morphologically consistent with the features of primary HCC $(\times 400)$

The recurrence of HCC can be detected by an elevated serum AFP or imaging findings. ${ }^{13}$ AFP is also known as an independent prognostic factor for HCC and a markedly elevated serum AFP level may reflect advanced HCC in terms of its large size or metastasis. ${ }^{14}$ In our review of the 11 cases of metastatic HCC to the ovary (Table 1), all cases showed elevated serum AFP levels, except one case (case no. 6). Amongst the reported cases of HCC metastatic to the ovary, the serum AFP levels declined after surgery and rose again when recurrence occurred (case no. 2 and 4). Therefore, the serum AFP can be a useful indicator of recurrent HCC in the ovary and should be closely observed. The serum AFP level did not correlate with the size of the metastatic ovarian HCC, which might be due to the small sample size and the incomplete data set ( 3 of 11 patients' data on tumor size were missing).

A fluorine-18 fluorodeoxyglucose $\left({ }^{18} \mathrm{~F}\right.$-FDG) PET has a potential role in the detection of tumor recurrence of HCC patients ${ }^{15-17}$ because glucose metabolism assessed by ${ }^{18} \mathrm{~F}$-FDG PET is related to progression or aggressiveness of HCC. ${ }^{18,19}$ Park et al..$^{20}$ reported that a ${ }^{18} \mathrm{~F}-\mathrm{FDG} \mathrm{PET} / \mathrm{CT}$ scan has a relatively high sensitivity for the detection of extrahepatic metastases of HCC. In their data, the sensitivity of ${ }^{18} \mathrm{~F}-\mathrm{FDG}$ PET/CT was $60.9 \%$ for primary HCC and $85.7 \%$ for metastatic HCC. Further, they concluded 
Table 1. Summary of Seven Cases of Metastatic Hepatocellular Carcinoma Previously Reported and the Present Case

\begin{tabular}{|c|c|c|c|c|c|c|c|c|c|c|c|}
\hline $\begin{array}{l}\text { Case } \\
\text { No. }\end{array}$ & Age & $\begin{array}{l}\text { Metastatic } \\
\text { site }\end{array}$ & $\begin{array}{l}\text { Clinical } \\
\text { features }\end{array}$ & $\begin{array}{l}\text { Size } \\
\mathrm{cm}\end{array}$ & $\begin{array}{c}\text { AFP elevation, } \\
n g / \mu \mathrm{L}\end{array}$ & $\begin{array}{l}\text { Time-to- } \\
\text { recurrence }\end{array}$ & $\begin{array}{l}\text { Previous treat- } \\
\text { ment }\end{array}$ & Treatment & $\begin{array}{l}\text { Other meta- } \\
\text { static lesions }\end{array}$ & $\begin{array}{c}\text { Disease } \\
\text { progression }\end{array}$ & $\begin{array}{c}\text { Year } \\
\text { reported/ } \\
\text { Reference No. }\end{array}$ \\
\hline 1 & 36 & Lt. & No & 6 & Yes; 18,800 & $12 \mathrm{mo}$ & $\begin{array}{l}\text { RL } \\
\text { Lt. liver partial } \\
\text { resection }\end{array}$ & TAH c BSO & No & & $1983^{9}$ \\
\hline 2 & 38 & Lt. & No & - & Yes; 14,819 & $3 \mathrm{mo}$ & $\mathrm{RL}$ & TAH c BSO & No & $\begin{array}{l}\text { Lung } \\
\text { metastasis }\end{array}$ & $1992^{11}$ \\
\hline 3 & 31 & Bilateral & Back pain & - & Yes; 2,700 & $\begin{array}{c}\text { Synchronous } \\
\text { metastasis }\end{array}$ & No & BSO, liver biopsy & Multiple HCC & $\begin{array}{l}\text { Bone } \\
\text { metastasis }\end{array}$ & $1992^{11}$ \\
\hline 4 & 68 & Bilateral & $\begin{array}{l}\text { Palpable } \\
\text { mass }\end{array}$ & - & Yes; 11,000 & $\begin{array}{c}\text { Synchronous } \\
\text { metastasis }\end{array}$ & No & BSO, omentectomy & $\begin{array}{l}\text { PC, para-aortic } \\
\text { LN }\end{array}$ & & $1992^{11}$ \\
\hline 5 & 56 & Lt. & $\begin{array}{l}\text { Anemia, } \\
\text { mass }\end{array}$ & 15 & Yes; 534 & $\begin{array}{c}\text { Synchronous } \\
\text { metastasis }\end{array}$ & No & $\begin{array}{l}\text { TAH c BSO, } \\
\text { sigmoid colostomy }\end{array}$ & $\mathrm{PC}$ & & $1999^{21}$ \\
\hline 6 & 47 & Rt. & Mass & 20 & No; 4 & $2 \mathrm{yr}$ & Orthotopic LT & BSO & No & $\begin{array}{l}\text { Rib } \\
\text { metastasis }\end{array}$ & $2000^{22}$ \\
\hline 7 & 39 & Rt. & Syncope & 13 & Yes; >60,000 & $9 \mathrm{mo}$ & $\begin{array}{l}\text { TACE \#3 } \\
\text { CTX. }\end{array}$ & CTx. & $\begin{array}{l}\text { Lung, spleen, } \\
\text { para-aortic } \\
\text { LN }\end{array}$ & & $2004^{2}$ \\
\hline 8 & 40 & Bilateral & Mass & 11 & Yes; 2,150 & $13 \mathrm{mo}$ & TACE \#3 RFA & No treatment & $\mathrm{PC}$ & & $2006^{23}$ \\
\hline 9 & 61 & Rt. & $\begin{array}{l}\text { Pain, con- } \\
\text { stipation }\end{array}$ & 10 & Yes; 350,000 & $5 \mathrm{mo}$ & PEIT & TAH c BSO & No & & $2001^{24}$ \\
\hline 10 & 43 & Lt. & Pain, mass & 6.5 & Yes; 140 & $\begin{array}{c}\text { Synchronous } \\
\text { metastasis }\end{array}$ & No & TACE, CTX & $\mathrm{PC}$ & & $2005^{25}$ \\
\hline 11 & 43 & Rt. & No & 7 & Yes; 336,520 & $23 \mathrm{mo}$ & $\begin{array}{l}\text { RPS } \\
\text { TACE \#3 } \\
\text { LMS }\end{array}$ & RSO & No & & $\begin{array}{l}\text { Present } \\
\text { case }\end{array}$ \\
\hline
\end{tabular}

AFP, alpha-fetoprotein; RL, right hemihepatectomy; LT, liver transplantation; TACE, transarterial chemoembolization; CTx, chemotherapy; RPS, right posterior sectionectomy; LMS, left medial sectionectomy; TAH c BSO, total abdominal hysterectomy with bilateral salpingo-oophorectomy; HCC, hepatocellular carcinoma; PC, peritoneal carcinomatosis; PTI, percutaneous ethanol injection therapy.

that large HCC ( $>5 \mathrm{~cm})$ had high sensitivity $(92.8 \%)$. In the present case, we also identified the site of recurrence using ${ }^{18} \mathrm{~F}-\mathrm{FDG}$ PET. Therefore, PET is a useful diagnostic modality for detecting the recurrence of HCC.

The diagnosis of metastatic ovarian HCC is a diagnosis of exclusion. In patients with a rising AFP following removal of primary HCC, a careful clinical assessment and abdominopelvic CT should be the first line of investigation. In the absence of intrahepatic metastases, a chest CT and bone scan should be added, followed by a CT/MRI of the brain. A PET scan is a useful tool in the diagnosis of extrahepatic metastasis of HCC, as demonstrated in our case. The ovarian metastasis can be further examined using pelvic US and is finally confirmed at laparotomy.

In conclusion, although metastasis of HCC to the ovary is very rare, one should have a high index of suspicion in a female patient with a lower abdominal mass and an elevated serum AFP level in the absence of other demonstrable metastases. Rational use of investigations such as CT or PET should help to confirm the diagnosis of this unusual metastasis.

\section{CONFLICTS OF INTEREST}

No potential conflict of interest relevant to this article was reported.

\section{REFERENCES}

1. Hong SS, Kim TK, Sung KB, et al. Extrahepatic spread of hepatocellular carcinoma: a pictorial review. Eur Radiol 2003;13:874882.

2. Kim TH, Cheung DY, Chung WB, et al. A case of metastatic hepatocellular carcinoma of the ovary. Korean J Gastroenterol 2004;43:215-218.

3. Masci G, Magagnoli M, Grimaldi A, et al. Metastasis of hepatocellular carcinoma to the heart: a case report and review of the literature. Tumori 2004;90:345-347.

4. Frigy AF. Metastatic hepatocellular carcinoma of the nasal cavity. Arch Otolaryngol 1984;110:624-627.

5. Font RL, Maturi RK, Small RG, Garcia-Rojas M. Hepatocellular carcinoma metastatic to the orbit. Arch Ophthalmol 1998;116:942945.

6. Yamanishi K, Kishimoto S, Hosokawa Y, Yamada K, Yasuno H. 
Cutaneous metastasis from hepatocellular carcinoma resembling granuloma teleangiectaticum. J Dermatol 1989;16:500-504.

7. Yasumatsu R, Okura K, Sakiyama Y, et al. Metastatic hepatocellular carcinoma of the external auditory canal. World J Gastroenterol 2007;13:6436-6438.

8. Oida Y, Ishii M, Dowaki S, et al. Hepatocellular carcinoma with metastasis to the pharynx: report of a case. Tokai J Exp Clin Med 2005;30:31-34.

9. Oortman EH, Elliott JP. Hepatocellular carcinoma metastatic to the ovary: a case report. Am J Obstet Gynecol 1983;146:715-717.

10. Ishikura H, Scully RE. Hepatoid carcinoma of the ovary: a newly described tumor. Cancer 1987;60:2775-2784.

11. Young RH, Gersell DJ, Clement PB, Scully RE. Hepatocellular carcinoma metastatic to the ovary: a report of three cases discovered during life with discussion of the differential diagnosis of hepatoid tumors of the ovary. Hum Pathol 1992;23:574-580.

12. Kishimoto T, Nagai Y, Kato K, Ozaki D, Ishikura H. Hepatoid adenocarcinoma: a new clinicopathological entity and the hypotheses on carcinogenesis. Med Electron Microsc 2000;33:57-63.

13. Zhou XD, Yu YQ, Tang ZY, et al. Surgical treatment of recurrent hepatocellular carcinoma. Hepatogastroenterology 1993;40:333336.

14. Wang CC, Iyer SG, Low JK, et al. Perioperative factors affecting long-term outcomes of 473 consecutive patients undergoing hepatectomy for hepatocellular carcinoma. Ann Surg Oncol 2009;16:1832-1842.

15. Yang SH, Suh KS, Lee HW, et al. The role of (18)F-FDG-PET imaging for the selection of liver transplantation candidates among hepatocellular carcinoma patients. Liver Transpl 2006;12:16551660.

16. Lee JW, Paeng JC, Kang KW, et al. Prediction of tumor recurrence by $18 \mathrm{~F}-F D G$ PET in liver transplantation for hepatocellular carcinoma. J Nucl Med 2009;50:682-687.

17. Yim HJ, Yeon JE, Byun KS, Lee CH, Choi SY, Kim SK. Laparoscopic resection of HCC implanted in the peritoneal cavity: a case detected by PET after hepatic resection. Hepatogastroenterology 2008;55:1549-1552.

18. Seo S, Hatano E, Higashi T, et al. Fluorine-18 fluorodeoxyglucose positron emission tomography predicts tumor differentiation, $\mathrm{P}$ glycoprotein expression, and outcome after resection in hepatocellular carcinoma. Clin Cancer Res 2007;13(2 Pt 1):427-433.

19. Yamamoto Y, Nishiyama Y, Kameyama R, et al. Detection of hepatocellular carcinoma using 11C-choline PET: comparison with 18F-FDG PET. J Nucl Med 2008;49:1245-1248.

20. Park JW, Kim JH, Kim SK, et al. A prospective evaluation of $18 \mathrm{~F}-$ FDG and 11C-acetate PET/CT for detection of primary and metastatic hepatocellular carcinoma. J Nucl Med 2008;49:1912-1921.

21. de Groot ME, Dukel L, Chadha-Ajwani S, Metselaar HJ, Tilanus HW, Huikeshoven FJ. Massive solitary metastasis of hepatocellular carcinoma in the ovary two years after liver transplantation. Eur J Obstet Gynecol Reprod Biol 2000;90:109-111.

22. Khunamornpong S, Siriaunkgul S, Chunduan A. Metastatic hepatocellular carcinoma of the ovary. Int J Gynaecol Obstet 1999;64:189-191.

23. Lim TK, Uhm JE, Shin JA, et al. A case of hepatocellular carcinoma with ovarian metastasis. Korean J Med 2006;71:573-576.

24. Park JH, Han CD, Huh CK, et al. Hepatocellular carcinoma metastatic to the ovary: one case report and review literature. Korean J Obstet Gynecol 2001;44:1900-1904.

25. Kim MJ. A case of metastatic hepatocellular carcinoma of the ovary: an immunohistochemical study and literature review. Korean J Pathol 2005;39:287-290. 